\title{
The Use of Nigerian Pidgin in Political Jingles
}

\author{
Joseph Babasola Osoba \\ University of Lagos, Nigeria
}

\begin{abstract}
The evolution of Nigerian Pidgin (NP) may be linked to the contact between the English language and Nigerian languages during the pre-colonial and post-independence periods. At its incipient stage, NP was rightly dubbed Pidgin English and sometimes also referred to as Broken English. Both references simply point to the fact that NP was regarded as a variety of the English language, more or less, especially since English appears as its superstrate, and Nigerian languages such as Hausa, Igbo, and Yoruba its substrates. But since independence, when as a result of the extensive use of the language by Nigerians from diverse ethnic extractions who had to communicate with one another, NP has begun to perform greater roles and more functions apart from its earlier contact function between Europeans and Nigerians. Within a period of fifty years, its limited use gave way to an extensive and elaborate use, thus changing the status of NP forever. It is in this light that I attempt
\end{abstract}

\footnotetext{
Joseph Babasola Osoba

Department of English, University of Lagos, Akoka, Yaba, Lagos, Nigeria

Phone: +2348060146303; Email: jbosoba@gmail.com
}

Received September 10, 2013; Revised November 23, 2013; Accepted January 7, 2014. 
to investigate and analyse the use of NP for political campaigns and jingles. An insightful account of the socio-cultural/political relationship between English and NP is presented.

Keywords: Nigerian Pidgin, Pidgin English, Broken English, political jingles

\section{Introduction}

Sociolinguistically, Nigeria may be described as a multi-lingual, multi-ethnic, and multi-cultural nation because of its diverse cultures, ethnic groups, languages, and religions. Politically, she may be seen as bilingual because of her adoption of English and all of her three major indigenous languages for official purposes. Historically, the contact between Nigerians and the British merchants, missionaries, traders, explorers, and the colonialists may be seen to be responsible for the roles, statuses, and functions of English in Nigeria today. It may also be seen as the precipitating factor for the emergence of NP, initially, as an incipient pidgin and now as a full-fledged language playing an extensive role in lives of its Nigerian speakers. The growth and development of NP may therefore be ascribed to the country's socio-political and cultural as well as colonial background. Its current function as the language of political campaigns and jingles in Nigeria however may be attributed to the growth and development of the mass media in the country since the 1980s. Agheyisi (1984: 213) aptly observes that

This is as a result of the prominence it has come to receive in recent years in the mass media throughout the country. In fact, the most effective outlet for NPE (NP) on its route to popularity has been the country's media. It is used extensively in the national radio networks for 
advertisement of various consumer goods, . . . Many of its speakers in the cities fondly refer to it as "the common man's language."

This observation seems to be strongly supported by Faraclas's (1996: 3) claim that “. . . at every stage of its history, Nigerian Pidgin has been used primarily as a means of communication among Nigerians rather than between Nigerians and traders, missionaries, or other foreigners." In fact, Faraclas (ibid.) suggests that NP "has become one of the biggest languages in Africa and the most widely spoken pidgin language in the world." Elugbe \& Omamor (1991: 147) provide an insight into the first attempt to use NP as a language of political campaigns and dating back to 1983 as follows:

Neither party slogans nor campaign literature are ever in NP. The only possibly significant change occurred recently (1983) at Ibadan. Radio O-Y-O (the Broadcasting Corporation of Oyo State) employed the service of Mr. Ikem Emordi of the University of Ibadan to give NP translation of Chief Obafemi Awolowo's campaign address at Mapo Hall grounds. Mr. Emordi also described the setting, the crowd, the dignitaries, and so on to $\mathrm{O}-\mathrm{Y}-\mathrm{O}$ listeners in NP. On that same occasion, Hausa and Igbo versions were aired alongside versions in English, Yoruba, and NP.

From the insight above, it becomes clear that until recent times politicians barely see any need for the use of NP in their political activities. Before the 1980 s, Nigerian politicians did not seem to have the temerity to address their audiences in NP. A possible reason is the fear that people might feel slighted if NP would be used as the main language of the political campaign, for the low status attributed to the language. During this period, everyone 
seems to have prided him/herself in the use of Standard English and the three major languages: Hausa, Igbo, and Yoruba. The then-politicians were afraid that their audiences might feel looked-down upon if they used NP in addressing them. Moreover, there was a strong negative attitude towards the use of NP among the public during this period. The reason for this sort of attitude is simple. Most Nigerians, even total illiterates, want to be associated with English or its use because it carries some prestige that no other (whether indigenous or not) languages carry. Thus no sensible politician would dare attempt to use NP in his or her address to the people. In fact, as then and to some extent till now, NP did not and does not today seem to confer any significant social status on its speakers. It is assumed that NP is the language of the common man, hence it is for the people of the lower classes. This statement seems to ring true to some extent. Even though both educated and non-educated Nigerians speak NP, it tends to be more common among the poor masses and barely literate people, especially bus-conductors, touts, area boys and girls, market women, and traders. This is perhaps why educated Nigerians deride its use. Elugbe \& Omamor (1991: 143) clearly explicate this fact:

NP's lack of status stems, as in case of other Nigerian languages, from the fact that ability to speak it confers no social advantage on the speaker. In popular soap-operas around the country, NP is put in the mouth of houseboys, messengers, village layabouts, and other such characters with no social standing. On the other hand, businessmen, councillors, politician, and so on are made to speak some kind of Broken English in which the rules of standard form are mercilessly assaulted and put to the sword. That broken form of English . . . is thus presented as superior to NP. 
This brief introduction highlights the genesis, as well as the background, to the use of NP in the media and by politicians in Nigeria. I shall now examine the mass media and the language of advertising in Nigeria.

\section{Mass Media Language of Advertising in Nigeria}

Advertising may be said to be as old as the mass media in Nigeria. Media history began in the country during the colonial period when nationalists such as Dr. Nnamdi Azikwe and Chief Obafemi Awolowo established their private newsprint media to wrestle political power and Nigeria's independence from the British colonialists. In fact, one could describe the pioneering effort of these nationalists as the precipitating catalyst for the growth and development of the mass media in Nigeria. Uche (1989: 40) relates the initial experience thus:

The former Western Region, which became the first to set up its own broadcasting system in 1959, started the first television broadcasting not only in Nigeria but also in the entire continent of Africa. Seven months later, in May 1960 , it initiated a radio broadcasting system over Western Nigeria Broadcasting Service (WNBS). One critic described the inception of the Western Region's broadcasting system as "bold and imaginative in planning."

It was noted that WNBS was highly successful in commercial advertising because of the heavy population of Lagos and Ibadan which provided ready and easy markets to exploit. Seeing the success of the effort of the Western Region, in 1962, the Northern Region established its own stations following the Eastern Region 
which had established its own on October 1st, 1960. Sooner than later, politicians began to see not only the commercial success of those stations but also their values as political instruments. Little wonder, Uche (ibid.: 42) notes this fact also:

However, the purpose of the regionalisation of the broadcast media, and The print media, was not solely for commercial reasons. They were used as powerful political instruments for the integration of each region and cultivation of regional awareness more than national consciousness and integration.

As a result of this realisation by Nigerian politicians, emphasis on and strict adherence to the use of English as a sole language of political campaign and jingles began to wane and decline considerably. Politicians have come to realise that they must canvass for votes in the language of the masses if they want to earn their votes which they cherish so much that, most time, they wish they could just pay in either cash or kind for it. In fact, for some of the politicians it is a matter of life and death and getting into a political office is a do or die issue. Nigerian Pidgin becomes therefore an easy and a ready-made tool for their campaigns and jingles. Thus in 1993, during the presidential campaigns, the late Chief Moshood Kashimawo Olawale Abiola, the presidential candidate for the Social Democratic Party (SDP) and Alhaji Bashir Othma Tofa, presidential candidate of the National Republican Convention (NRC), employed NP extensively, especially on the radio and television, in their campaigns and jingles. This shift from the use of English to the use of NP for political communication has become expedient for Nigerian politicians with ambition of reaching the largest number of the Nigerian masses at the grassroots level. Since then, and up to the present, politicians have been inceasingly attracted and fascinated by the use of NP for mass media adverts and jingles. Ugoagwu 
(2006: 61) in an article entitled, "Vernacular, Plain, and Simple," aptly captures the current thinking of scholars and researchers in Nigerian languages in his illuminating explication of the advertising scenario in the country as follows:

I am of the opinion that our communications efforts have not taken advantage of the strategic importance of our local languages. Most agencies are slow to recommend that commercials be done in Nigerian local languages. Their argument is that producing commercials in our mother tongues brings down the brand and takes away from its premium positioning. Yet you cannot remove from the magic of commercials done in Yoruba, or pooh-pooh the beauty of the ones rendered in Igbo. If you listen to jingles done in Hausa language, you would agree that there is nothing like speaking to a people in their local language. In the last political campaign, the most interesting political advertisements as far as I was concerned were the ones done for the Governors of Lagos and Ogun States. They were both done in Yoruba, using local brands of music. People never failed to respond to these beautiful commercials anytime they were aired on television. Nigerians would agree with me that commercials done even in pidgin English (our Nigerian version of English) has more communication power, is far more entertaining and definitely more far reaching.

One cannot but agree with Ugoagwu's (ibid.) opinion and insight because they express the reality of the current situation in the use of local and pidgin languages as advertising language. Political advertising, in the form of radio campaigns and jingles, relates to the technique of communicating with the masses of the people through the electronic medium in the language of the common man. The sheer number of the grassroots people in terms 
of their votes makes them indispensable to desperate politicians who want to win elections at all costs and by all means. Thus these politicians would employ every means possible to win their votes, especially when NP provides the easiest means of reaching them. His insight is further buttressed by the following (ibid.):

There are more reasons why we should begin to seriously consider doing more advertisement in our local languages. Chief among them is that part of the duty of advertising is to preserve and promote the values and culture of a people, or at least reflect them. Local languages are rich in idioms, proverbs, innuendoes, puns, alliterations, and witty sayings. These are gradually being forgotten as we lean more towards the English language.

Since the major goal of every advert is primarily to convince or persuade its audience, political advertisers would readily employ the most convenient means or language to convince or persuade the electorate about their political programmes. Thus, some politicians, political jobbers, and their cronies have found NP an easy tool for their media campaigns and jingles. Statistics, as at 1990 , shows that only $5 \%$ of the entire Nigerian population speak the English language, which is the official language in Nigeria 1 whereas evidence suggests that more than $70 \%$ of the entire Nigerian population speak or use NP either as mother tongue or as a primary or common language (see Donwa-Ifode 1984, Elugbe \& Omamor 1991, Osoba 2000). As at 1994, about eighteen million $(18,000,000)$ Nigerians listened to the radio. ${ }^{2}$ The point here is that if $17 \%$ of eighteen million Nigerians who listen to the radio speak NP then a campaign or jingle in NP may be assumed to reach a large proportion of the Nigerian population. Thus it is

1 See Atlaspedia Online (http://www.atlapedia.com/online/countries/nigeria.htm).

2 See Atlaspedia Online (http://www.atlapedia.com/online/countries/nigeria.htm). 
quite surprising that, among the eighteen presidential candidates contesting for the April 2011 elections in Nigeria, as at the first week of March 2011, only one of them had used NP, in addition to English, in their radio campaigns and jingles. The only presidential candidate is the incumbent President Goodluck Ebele Jonathan of the People's Democratic Party, PDP.

This was due to the problem of acceptability and low social rating that NP faces generally in Nigeria. This perhaps was why Mafeni (1971: 99) argued that "Attitudes to pidgin are complex and ambivalent. Many Nigerians, although they use pidgin as a register in certain familiar contexts, are nevertheless ashamed to be associated with the language in public . . ." Other problems include the view of the elite that pidgin is a debased form of standard English and thus a language for the lower class and the "unenlightened" as well as the threat posed by English as a dominant language in Nigeria (see Fawehinmi 1987). Akinnaso's (1989: 136) observation aptly summarises this point:

.. . the rivalry between English and pidgin English as linguae francae. While English continues to perform "high" functions, pidgin English has almost taken over the role of lingua franca in non-formal domains. Thus, it has become the most popular medium of intergroup communication in various heterogeneous communities throughout the country . . . However, partly because it is still largely associated with illiterate or uneducated users, partly because it is viewed as a "corrupt" form of language, and partly it poses a threat to standard Nigerian English, which is taught in schools and used in formal, official settings, pidgin English is stigmatised. Consequently, it has had no place in the nation's language policies, despite its increasing role as a lingua franca.

It seems clear that most of the Nigerian elite would not 
114 The Use of Nigerian Pidgin in Political Jingles

associate themselves with NP. For instance, even though Akinnaso's (ibid.) comment may be regarded as complimentary, his reference to NP as pidgin English is derogatory and may be seen as a betrayal of his trust in its potential to play a "high" social or official function in Nigeria.

\section{Political Campaigns and Jingles in Nigeria and the Ideology of Advertising}

Political campaigns and jingles can be described as inherent features of every democratic set-up. In Nigeria, they were used in the late 1950s and early 1960s, when the fathers of Nigeria's politics such Alhaji Abubakar Tafawa Balewa, Dr. Nnamdi Azikwe, and Chief Obafemi Awolowo, conducted their campaigns in English and the three major indigenous languages depending on the peculiarity of their audiences. In the 1979 and 1983 elections, the political climate of Nigeria became more exciting as politicians such as Chief Awolowo had to employ expert pidgin speakers to address their mixed audiences in NP. This may be described as a turning point in the history of electioneering campaigns in the country. However, the use of NP for campaigns and jingles, in addition to English, Hausa, Igbo, and Yoruba could be said to be limited or restricted during this period. This is as a result of the fact that only few politicians thought it wise to use NP to campaign because of the effect of the social stigma attached to the language at this period. Apart from places such as Benin, Warri, Sapele, Calabar, and Port-Harcourt, hardly any noticeable politicians used NP in their campaigns whether in the public or in the media. Nevertheless, many of them had begun to notice its usefulness especially in communicating with the grassroots people as a language of the common man. Jibril's (1995: 233) view is instructive as follows: 
Today, the functions of NP have become more extensive. Apart from expanding its territorial spread as a lingua franca in ethnically heterogenous areas such as Warri, Sapele, Port-Harcourt, Lagos, Abuja, and other large cities, and among the lower ranks of the security forces, it is now used in radio and television broadcast and in poetry and drama. Its use in radio broadcasts was pioneered by Radio Rivers FM Station, Port-Harcourt, in 1984 . . . The FM Stations nationwide tend to favour NP for several programmes as the language of the masses.

In 1999, the presidential campaigns of Chief MKO Abiola of SDP and Alhaji Tofa of NRC became the most fascinating till today because of their profuse use of all major languages including English and manipulation of the languages to suit different occasions and audiences. The electronic media campaigns and jingles were employed to appeal to their prospective voters. Besides English, Hausa, Igbo, and Yoruba, NP was also used by both presidential candidates to canvass for votes. The manipulation of Alhaji Tofa's NP radio jingle was dramatic, hilarious, fascinating, and communicative as the following sample illustrates:

(1) Tofa o o o, Tofa; Tofa o o o, Tofa Tofa yu don win o, Tofa; Pata pata yu go win fo efa, Tofa. 'Tofa o o o, Tofa; Tofa o o o, Tofa

Tofa, you have won indeed, Tofa; totally, you shall win always.'

(Source: Radio Nigeria 2, Lagos)

Alhaji Tofa's NP radio jingle (1) was changed by Chief MKO Abiola's supporters to (2) below.

(2) Tofa o o o, Tofa; Tofa o o o, Tofa

Tofa yu don luz o, Tofa; Pata pata yu go luz fo efa, Tofa. 
'Tofa o o o, Tofa; Tofa o o o, Tofa

Tofa, you have lost indeed, Tofa; totally, you shall lose always.'

(Source: Radio Nigeria 2, Lagos)

The fact that politicians have found it useful to adopt NP in their campaigns and media jingles seems to be a pointer to the reality of its sociolinguistic significance. Media jingles tend to be socially relevant in terms of their persuasive features and ideological assumptions. Thus they are subject to both discourse and sociolinguistic enquiries. In fact, media jingles may be seen to be more useful to the society in terms of their ideology of advertising than in terms of their nature as or use for persuasive communication which is aimed at selling things (see Fairclough 2001: 167).

From a broad perspective, Fairclough (ibid.) examines the features of advertisements that the British Code of Advertising Practice is directed to control and observes that it only takes account of only the explicit claims while ignoring the implicit side of truth in discourse, ideology. Thus his emphasis seems to be that the social or ideological aspects of any form of advertising are as important as its strategic or persuasive nature. This is of great significance in relation to political campaigns and jingles because politicians are not only persuading but also establishing relations with the electorate in their campaigns and jingles. The summary of his perspective on how advertisements work ideologically is highlighted as follows:

(3) a. Building relations:

Advertising discourse embodies an ideological representation of the relationship between the producer/advertiser of the product being advertised and the audience, which facilitates the main ideological 'work.' 
b. Building images:

Advertisements get their audiences to draw upon ideological elements in their MR in order to establish an 'image' for the product being advertised.

c. Building the consumer:

Advertisements, using 'images' which audiences 'help' to generate for products vehicles, construct subject positions for 'consumers' as members of consumption communities.

These assumptions may constitute tools of a social theory in terms of their relevance and adequacy in illuminating significant features of media jingles. For instance, the power relations between Nigerian politicians and the electorate may aptly be captured in the way Nigerian politicians, through their agents, identify themselves with the masses through a language (NP) that is associated with them. Thus the use of NP in their jingles helps them build a positive image since the masses may now consider them as being in solidarity with their social status and therefore accommodating their yearnings and aspirations in terms of political dividends.

In a bilingual or multilingual community such as Nigeria, social interaction may involve different levels or varieties of or even different languages (evidence suggests that over 500 languages are spoken in Nigeria (see Akinnaso 1989, Bamgbose 1995)). In this regard, the choice of the appropriate language, form, or variety may be determined by factors earlier mentioned such as sex, context, relationship, and setting. The situation in Nigeria seems somewhat complex because of the use of NP which has been described either as pidgin or creole (see Donwa-Ifode 1984, Elugbe \& Omamor 1991) or even a variety of English. Adeniran (1987: 27) provides an interesting insight as follows:

Thus in a community which features bilingualism with 
diglossia, there coexist code matrices, i.e., specific codes for different communicative roles. The verb repertoire of a bilingual or multilingual member of this community comprises not only of distinct languages but conceivably also of dialects and sociolects of particular ones. From the network, he makes choices but against a background of knowledge of the determinants of communication present and functional in a particular communication act.

As an incipient pidgin, NP played the role of a contact language but, with its growth and development, it has become the language of the common man as a significant lingua franca in Nigeria (see Mafeni 1971, Elugbe \& Omamor 1991, Faraclas 1996). Moreover, its role as a language of social interaction cuts across all social strata. From the 1980 s to the present, it has played and is still playing a significant role as a language of mass media and social and commercial communication. Hudson's (2001: 63-64) view provides some insight as follows:

From a social point of view, creoles are of more interest than pidgin. Most creole languages are spoken by the descendants of African slaves and are of great interest, both to their speakers and to others, as one of the main sources of information of their origin and as a symbol of identity.

Based on this perspective, one may assume erroneously that only the descendants of freed slaves speak NP. On the contrary, NP is spoken by Nigerians from all walks of life and of all callings, sexes, religions, or ages. It is a common language for both literate and illiterate Nigerians. However, it should be clear from the very outset that NP is by no means homogeneous in form, structure, and function. As earlier outlined, varieties of NP exist side by side with the varieties of other languages in the 
country. The choice of a form or variety of NP to be used depends, to a large extent, on a number of factors, including socio-cultural, such as setting, audience, topic, purpose, class, profession, interlocutor, and even sex and age. But, interestingly, most, if not all, of its varieties tend to be mutually intelligible. Its mass media variety is the form or type that cuts across classes, sexes, professions, and ages. Because of the influence of the mass media, its multilingual environment and ethnic and political neutrality, it may eventually become the standard variety. In fact, as suggested by many prominent scholars (see Aghesyisi 1984, Elugbe \& Omamor 1991, Faraclas 1996), NP may eventually become one of, if not the only, Nigeria's national lingua franca. Todd (1981: 91) aptly observes that

Pidgins and creoles are languages which have facilitated and are still facilitating communication and freedom of movement in multilingual communities, and which are capable of expressing the ideals of their users. From the point of view of scholarly research they offer a new dimension in the study of linguistic history and provide data in the search for linguistic universals.

Social theory appears to be most relevant to the study of the function of NP as a language of mass communication. Looking at the social function of NP, it seems appropriate to regard the language as the most accessible and widespread lingua franca in Nigeria. It appeals to all or most Nigerian interlocutors, especially in their private, personal, and interpersonal life. The natural sense of humour that accompanies its usage is more or less a significant attraction to NP. So in any interpersonal situation involving spouses, peers, mates, colleagues, or even customers and traders from same or different linguistic or cultural backgrounds, NP comes in more handy than any other language in Nigeria. This point is well-noted by Jowit (1995: 47) in his observation that 
"Nigerian Pidgin has had its vocal advocates, predictably those who form the educated class in the southern part of the country."

From the social theory perspective, the concept of diglossia relating the different functions and roles of languages or their forms in a bilingual or multilingual community such as Nigeria is most appropriate as an analytical tool for the study of NP in its role as a language of political campaigns and jingles in the Nigerian media. Apart from English, Hausa, Igbo, and Yoruba used by politicians for their campaigns, no other language is more readily used than the NP especially in the media. One could regard the English language and the three major languages as being more formal, in a sense, than the NP, especially in the political context and situation in Nigeria. While most Nigerians would naturally employ the use of those four languages in formal and semi-formal situations, no one would use NP except in purely informal, intimate, and, perhaps, hilarious situations. This is not to say that NP cannot be used in formal situation but it is the context of usage that determines its appropriateness. Fawehinmi (1987: 81) is quite optimistic about the prospects of NP. To him, "Regardless of its lack of political base and other sociolinguistic problems, the potential communicative values of pidgin in the fields of entertainment, social interaction, and Mass Communication must be duly acknowledged. However, there is need for concerted efforts in this direction to further improve the potential communicative value of the language and enhance its social acceptability."

\section{Methodology}

The methodological approach employed in this study involves the tape recording and transcription of a corpus. Introspection or intuition was also used sometimes to clarify grey areas. The NP 
data for this study was obtained from Radio Nigeria 2, WAZOBIA FM and Eko FM political advertorials and jingles. The data was listened to, recorded, and transcribed as aired on the two stations. The advertorials in English, Hausa, and Igbo were not obtained for obvious reasons of time, space, relevance, and bulkiness. The texts were then organised into their constituent sentences/clauses without reference to their textual components which account for the thematic organisation and the information structure of their propositional content of the sentence. Descriptive tools were applied for the purpose of analysis.

(4) Presentation and analysis of data

a. Text 1 (Radio Jingle by and for Alhaji Bashir Tofa, the NRC 1993 presidential candidate)

i. Tofa o o o, Tofa; Tofa o o o, Tofa; 'Tofa o o o, Tofa; Tofa o o o, Tofa'

ii. Tofa yu don win o, Tofa; 'Tofa, you have won indeed, Tofa'

iii. Pata pata yu go win fo efa, Tofa. 'Totally, you shall win always, Tofa.'

b. Text 2 (Radio Jingle for President Jonathan \& Alhaji Sambo)

i. Na so so front frog de jump de go!

'It is normal for the frog to leapfrog continuously!'

ii. Wai he be sey, fo dis taim fo we country life, we stil de tink of hau we go selekt leader them fo di seik of di part of di kontri he kom from?

'Why is that, at this time in our national life, we still choose our leaders based on their ethnicity?'

iii. $\mathrm{Na}$ president wey go tanda kokoroko to lead us as 'one Nigeria' we want, to show sey we be one ogbonge kontri!

'It is a president who is bold and courageous to lead 
us as one nation that we want, to show that we are a united strong country!'

iv. Na Jonathan and Sambo leadership get that answer for united Nigeria.

'It is Jonathan and Sambo leadership that has the solution for a united Nigeria.'

v. Dis message, na from di 'United Nigeria Group.' United de act kakaraka.

'This message is from the United Nigeria Group. United acts firmly.'

\section{A Sociolinguistic Appraisal}

Face, as a socioliguistic concept, may be described as the public image that the speaker presents to the world. Thus face refers to the various kinds of social information about the speaker as noted by Hudson (2001: 230). His explication is instructive, as the following shows:

Your face ... is a complex cluster of characteristics . . . On the one hand, it is linked to your observable behaviour ... ; so if you behave differently, the face you project may change. On the other hand, it is linked to various personal and social characteristics which may not in themselves be directly observable. In this respect your face is just a word, which combines an observable form with an unobservable meaning; and just like a word, it is a prototype - defined by cases, with exceptions allowed ... The result of combining observable and unobservable characteristics in a prototype is that the way you speak tells the rest of us about your face, i.e., about the kind of person you want us to think you are. 
It is interesting to note that the jingles for both Tofa and Jonathan in this wise may be seen as representing their faces socially and politically. Medially, their agents were speaking words in their jingles, on their behalf, depicting their socially observable and unobservable characteristics. The way their agents, in the jingles, spoke tells the rest of us a lot about their faces.

Tofa is presented as a winner in terms of face. His jingles, which is couched as a song, tells us that he is a winner and will remain a winner politically. But the opposition changed his "winner face" to a "loser face" in their song which changed the word "winner" to "loser." Thus the positive face of winner was changed to a negative face of loser. This may then be considered the principal reason why Alhaji Tofa lost in the 2003 presidential election: his winner face was changed to the loser face by the opposition, through the media jingle, in the mind of the masses of Nigerians who constituted the main electorate, those who actually voted against him. This seems to be the fact even though the election, which was adjudged the best by both local and international observers in the country till then, was eventually annulled by the military regime of General Ibraham Babangida. Thus words and expressions like "winner" and "don win o" were changed to "loser" and "don lose o" which are observable forms can easily be transformed in the mind of the mass of the electorate either from positive meaning to a negative meaning or vice versa. The positive social relations which the jingle was initially meant to establish had been changed to a negative one; instead of voting for Alhaji Tofa, the masses voted against him in the election. This happened because of the negative face which the opposition gave to his original positive face.

On the contrary, President Jonathan's jingle was not changed by the opposition. The positive face portrayed in the jingle was accepted by the electorate as so. Little wonder, he won the election with a landslide victory. Words and expressions like "tanda kokoroko," "one Nigeria," "Jonathan and Sambo leadership 
get that answer for united Nigeria," and "one ogbonge country" seem to have made the electorate think that President Jonathan would be a good leader for Nigeria, hence his election victory. Those expressions gave him a positive face because of the positive interpretation or meaning that the Nigerian electorate gave them. This exactly is the kind of face that his agents wanted him to have with the electorate and this might be why he won the 2011 presidential election .

The concepts of "Solidarity" and "Accommodation" are of direct relevance here. Solidarity is said to be that relationship that reflects shared experience, which is necessarily tied to linguistic similarity. According to Hudson (2001: 232), "People who have spent all their life together, sharing the same experiences of language, are bound to be very similar in language; and conversely, similarity of language is a good . . . basis for guessing similar experiences." Thus it may be assumed that politicians who use NP in jingles are only trying to identify with their Nigerian masses. Accommodation is described as the desire to reduce differences in behaviour in order to stress solidarity. The use of NP by the agents of Ahaji Tofa and President Jonathan can be seen as an expression of solidarity through accommodation. By using the same or similar language as the Nigerian masses, the agents were trying to show that their candidates identified with them by association and accommodation. It then seems that the use of NP, which is the language of the masses in Nigeria, by politicians and their agents is an attempt to express their solidarity with and accommodation of the Nigerian people. This in turn makes the people to identify with them, giving them full support through their votes.

The concept of power is also relevant here. Power may be described as an interpersonal relationship which is important for the basic organisation of society in terms of social classes, with the rich and powerful at the top and the poor and powerless at the bottom (ibid.: 240). This is the social relation presented in Alhaji 
Tofa's jingle. He was presumed to win, so he was seen as being on top and powerful against the social class of the poor and powerless Nigerian masses. Thus the masses refused to vote him into power. He was seen as not being in solidarity with the masses by calling himself already a winner even before the election. Though he used the language of the masses, NP, his choice of words portrayed him as being far from the masses. So they also refused to identify with him or his class.

The jingle for President Jonathan was seen as transferring power to the masses since they were regarded as the ones to choose or elect their own leaders. Moreover, the use of expressions like "tanda kokoroko" and "ogbonge kontri" might have helped in showing solidarity and accommodation for the masses and their social class. Thus here power is seen as belonging to the Nigerian people. We may therefore not be surprised that President Jonathan and Ahaji Sambo won the 2011 presidential election.

\section{Conclusions}

From the foregoing, it is clear that the use of NP for political jingles is appropriate, relevant, and illuminating in sociolinguistic studies. The new roles and functions which NP is beginning to perform may be a pointer to the fact that it may become a linguistic bedrock of Nigeria's political communication and development. Hopefully, the negative attitude of the political and educated class may change as they witness the transformation of NP as a tool for political advancement and success. Thus the use of NP in the political jingles of Alhaji Tofa and President Jonathan might be said to mark a watershed in Nigerian political development. This may serve as a pointer to the fact as the Nigerian society is developing socially and politically, the influence of NP and its acceptance rate may also be growing 
among the educated and the political elite. Contextually, the use of NP by politicians, no matter how few they may be, seems to forecast its future social and political acceptance and influence. Finally, the concepts of power and solidarity are shown to be very relevant in our analysis of the social functions of NP used in political jingles as exemplified by the jingles for Alhaji Tofa and President Jonathan.

\section{References}

Adeniran, A. 1987. Sociolinguistic Perspectives on Human Communication. In S. Unoh (ed.), Topical Issues in Communication Arts 16-33. Uyo: Modern Business Press.

Agheyisi, R. 1984. Linguistic Implications of the Changing Role of Nigerian Pidgin English. English Word-Wide 5, 211-233.

Akinnaso, F. 1989. One Nation, Four Hundred Languages: Unity and Diversity in Nigeria's Language Policy. Language Problems and Planning 13.2, 133-146.

Bamgbose, A. et al. 1995. New Englishes: A West African Perspective. Ibadan: Mosuro.

Donwa-Ifode, S. 1984. Is Nigerian Pidgin Creolising? Journal of Linguistic Association of Nigeria 2, 99-203.

Elugbe, O. \& A. Omamor. 1991. Nigerian Pidgin: Problems and Prospects. Ibadan: Heinemann Educational Books Plc.

Fairclough, N. 2001. Language and Power. London: Pearson Education Limited.

Faraclas, N. 1996. Nigerian Pidgin. London: Routledge.

Fawehinmi, P. 1987. Communication in Pidgin in Nigeria: Origin, Problems, and Prospects. In S. Unoh (ed.), Topical Issues in Communication Arts 71-87. Uyo: Modern Business Press.

Hudson, R. 2001. Sociolinguistics. Cambridge: Cambridge University Press.

Jibril, M. 1995. The Elaboration of the Functions of Nigerian 
Pidgin. In A. Bamgbose et al. New Englishes: A West African Perspective 232-247. Ibadan: Mosuro.

Jowit, D. 1995. Nigeria's National Language Problem: Choices and Constraints. In A. Bamgbose et al. (eds.), New Englishes: A West African Perspective 34-56. Ibadan: Mosuro.

Mafeni, B. 1971. Nigerian Pidgin. In J. Spencer (ed.), The English Language in West Africa 95-112. London: Longman.

Osoba, J. 2000. Tense and Aspect in Nigerian Pidgin. Ph.D Dissertaion. University of Lagos.

Todd, L. 1981. Pidgin and Creoles. London: Routledge \& Kegan Paul.

Uche, L. 1989. Mass Media, People, and Politics in Nigeria. New Delhi: Ashok Kumar Mittal.

Ugoagwu, P. 2006. Vernacular, Plain, and Simple. Available at URL <http://yeyeolade.wordpress.com/author/yeyeolade/>. 